\title{
A Rare Complications of Sickle Cell Disease: Empyema and Chronic Subdural Hematoma
}

\author{
Tien Yu Song Miraulle, Bemora Joseph Synèse, Masina Ndalana D'assise, Rasolonjatovo Emilson \\ Charles, Andriamamonjy Clément, Mamiarisoa Rabarijaona, and Ratovondrainy Willy
}

\section{ABSTRACT}

\begin{abstract}
Sickle cell disease is a hemoglobinopathy responsible for many complications that are sometimes frightening. Brain damage is part of one of the complications that can affect the vital and/or functional prognosis of patients. We report two cases of neurological complications, patients with known homozygous sickle cell disease, admitted to the Resuscitation Service of the JRA University Hospital for neurological deficit of recent appearance. One presented a spontaneous bilateral chronic bilateral subdural hematoma, and the other an extradural empyema diagnosed on brain scan. The patients benefited from a neurosurgical intervention with favorable postoperative outcomes, marked by an improvement in neurological symptoms. This form of complication is relatively rare in patients with sickle cell disease. It is favoured by repeated vaso-occlusive crises responsible for vascular fragility following repeated ischemia and inflammatory phenomena. The surgical indication depends on the clinical condition and the radiological aspect
\end{abstract}

Keywords: empyema, sickle cell disease, subdural hematoma, surgery
Published Online: February 22, 2021

ISSN: $2736-5476$

DOI : 10.24018/ejclinicmed.2021.2.1.16

Tien Yu Song Miraulle

Department of Neurosurgery CHU JRA University of Antananarivo, Madagascar (e-mail:miraulletienyusong ${ }^{\circledR}$ hotmail.com) Bemora Joseph Synèse

Department of Neurosurgery CHU JRA University of Antananarivo, Madagascar Masina Ndalanad'assise

Department of Neurosurgery CENHOSOA Antananarivo, Madagascar

Rasolonjatovo Emilson Charles

Department of Neurosurgery CHU JRA University of Antananarivo, Madagascar Andriamammonjy Clément

Department of Neurosurgery CHU JRA

University of Antananarivo, Madagascar

Mamiarisoa Rabarijaona

Department of Neurosurgery CHU

Tambohobe Fianarantsoa, Madagascar

Ratovondrainy Willy

Department of Neurosurgery CENHOSOA

Antananarivo, Madagascar

\section{INTRODUCTION}

Sickle cell disease is an autosomal recessive genetic hemoglobin disorder characterized by the presence of an abnormal hemoglobin (hemoglobin S) [1]. African countries are the most affected countries. In Madagascar, it affects more than $10 \%$ of the population [2]. The prevalence found for AS and SS forms was $9.4 \%$ and $0.2 \%$ respectively [3].

It is a major public health problem and the occurrence of complications jeopardizes the vital and functional prognosis of patients. Its complications are numerous; those of neurological complications are rare and are represented by ischemic stroke, spontaneous hemorrhagic complications and intracranial infections

\section{OBSERVATIONS}

\section{A. Case 1}

This was a 17-year-old patient, known homozygous sickle cell disease, who presented with a headache of sudden onset with rapidly progressive aggravation. He was treated with PARACETAMOL, but without improvement with worsening of the symptomatology and progressive onset of right frontal swelling (Figure 1).

On physical examination the patient was febrile at $39^{\circ} \mathrm{C}$, icteric, with a Glasgow score of $15 / 15$ and there was no neurological deficit. The frontal swelling was painful, of soft consistency associated with homolateral palpebral edema.

Brain CT scan showed an image in favor of a left frontal empyema associated with frontal sinusitis that had intracranial communication (Figure 2) and fluid content of frontal swelling.

Biological examination showed anemia at $5.1 \mathrm{~g} / \mathrm{dL}$, hematocrit at $13.8 \%$, white blood cells at $9 \mathrm{Giga} / \mathrm{L}$, platelets at $670 \mathrm{Giga} / \mathrm{L}$, and Prothrombin at $78 \%$.

An evacuating puncture of the frontal subcutaneous collection was performed and sent for bacteriological examination and antibiotic susceptibility testing; the bacteriological examination identified Providenciarettgeri infection. A probabilistic antibiotic therapy was started and then secondarily adapted to the antibiogram with a favorable evolution of the clinical symptomatology. 


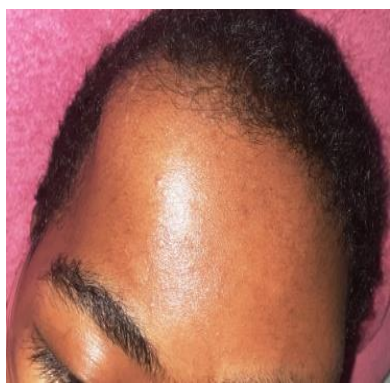

Fig. 1. Right frontal swelling

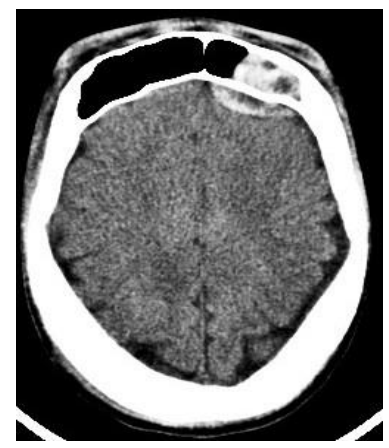

Fig. 2. a left frontal empyema associated with frontal sinusitis

\section{A. Case 2}

A patient aged 06 years, homozygous sickle cell disease known since the age of 03 years, had presented a progressive disorder of consciousness. In her antecedents, repeated vasoocclusive crises, ischemic strokes, absence of notion of head trauma.

She had presented a convulsive seizure which motivated her consultation. On physical examination, her hemodynamic status was stable, with a Glasgow score of 13/15.

The brain scan showed a bilateral chronic subdural hematoma measuring $28 \mathrm{~mm}$ thick on the left and $8 \mathrm{~mm}$ thick on the right, associated with diffuse cortical-subcortical atrophy (figure 3).

Biological examination showed hemoglobin at $94 \mathrm{~g} / \mathrm{dL}$, leukocytes at $6 \mathrm{Giga} / \mathrm{L}$, platelets at $252 \mathrm{Giga} / \mathrm{L}$, and Prothrombin at $88 \%$.

The patient had undergone neurosurgical intervention to evacuate the hematoma on the left side with an enlarged drill hole and placement of a subdural drain for 48 hours with a favorable outcome.

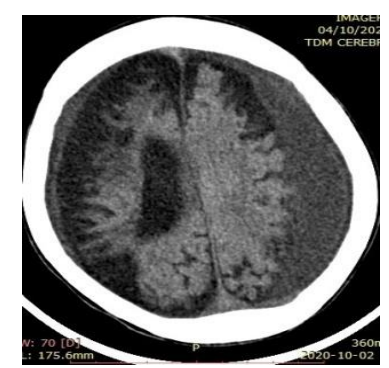

Fig. 3. Bilateral chronic subdural hematoma

\section{DISCUSSION}

Neurological complications are one of the major causes of morbidity and mortality in sickle cell disease, represented by ischemic stroke, intracranial hematomas and infections [4].

In our first case, it was an extradural empyema type infection and a frontal subcutaneous collection due to the Providenciarettgeri germ, which is a Gram-negative bacterium belonging to the Enterobacteriaceae family. According to the literature, pneumococcus is the first suspected germ before Haemophilusinfluenzae B in cases of intracranial infection [5]. Infections are common in sickle cell disease and can be severe. This susceptibility to infections can be promoted by [5]: functional asplenism, alteration of the complement pathway, which are proteins that participate in the phagocytosis of intruding germs, repeated vasoocclusive crises that lead to venous stasis and promote infections, especially of the skin.

In the second case, it was a rare intracranial complication of a type of bilateral spontaneous chronic subdural hematoma in a patient with a history of ischemic stroke. Ischemic stroke accounts for $50-80 \%$ of cases and increases with age [7]. The mechanism of a chronic subdural hematoma may be secondary to cerebral atrophy, leading to stretching of the cortico-dural vein, which is responsible for bleeding (found in the reported case). According to the literature, risk factors for bleeding in children with sickle cell disease are favoured by recent blood transfusion, high blood pressure and corticosteroid or non-steroidal anti-inflammatory drug use [8]. In the reported case, this patient has a history of recent repeated transfusion. On the other hand, a subdural hematoma may be secondary to a vaso-occlusive mechanism but often associated with bone damage and extradural hematoma [9]. The inflammatory phenomenon secondary to the adhesion of sickle cell adhesion to the vascular endothelium, which will be responsible for vascular fragility, is also responsible for the occurrence of this hemorrhagic complication.

\section{CONCLUSION}

Sickle cell disease is a challenge in terms of public health, both because of its complications, but also and especially because of the prolonged disabilities it is likely to cause. Neurological complications are rare and often serious but should be evoked in front of neurological signs and should benefit from an emergency brain scan.

\section{REFERENCES}

[1] Mattioni S, Stojanovic KS, Girot R, Lionnet F. La drépanocytose en France. Rev Francoph des Lab. 2016 Avril; 487:61-6.

[2] RAKOTONDRASOA N. Profil radiologique des patients drépanocytaires vus au Service d'imagerie du CHU Joseph RAVOHANGY ANDRIANAVALONA Antananarivo [Thèse]. Médecine humaine: Antananarivo: 2015.

[3] BarabeP, Charles D. L'hémolyse chronique et ses mécanismes dans la drépanocytose. Méd Trop. 1978; 38: $151-4$.

[4] Gill FM, Sleeper LA, Weiner SJ, Brown AK, Bellevue R, Grover R, et al. Clinical events in the first decade in a cohort of infants with sickle cell disease. Cooperativestudy of sicklecelldisease. Blood $1995 ; 86$ : 776-83.

[5] Emmanuelle L, Phippe R. Prévention des infections chez l'enfant drépanocytaire.Développement et Santé.2006 Aout $2 ; 182$.

[6] Philippe R. Infections et drépanocytose. Développement et Santé. 1982 fevr $26 ; 182$.

[7] Ohene-Frempong K, Weiner SJ, Sleeper LA, Miller ST, Embury S, MoohrJW , et al. Cerebrovascular accidents in sickle cell disease: rates and risk factors. Pub med. 1998 Jan 1; 91(1): 288-94. 
[8] Strouse J, Hubert M, Debaun M, Jordan L, Casela J. Primary hemorrhagic stroke in children with sickle cell disease is associated with recent transfuion and use of corticoids. Pub Med 2006 Nov; 118(5):1916-24.

[9] Cabon I, Hladky JP, Lambillotte A, Cotton A, Dhellemmes P. Uncommon etiology of extradural hematoma. Pub Med. 1997; 43(3):173-6. 